\title{
Sleep disturbances in children with ADHD: a study conducted at Hazrat Rasoul Akram Hospital, Tehran
}

\author{
H Shooshtari, R Bidaki, J Fili, H Zarafshan
}

\section{Introduction}

Attention deficit hyperactivity disorder (ADHD) is one of the commonest disorders seen in Child and Adolescent Psychiatry services. ADHD is associated with comorbid conditions such as emotional problems, aggression and oppositional behaviors, specific learning disorders and sleep problems Aims

The aim of the present study was to compare sleep problems in children with ADHD with that of a control group.

\section{Methods}

Ninety patients aged $6-12$ years diagnosed with ADHD were compared with controls $(n=90)$ without ADHD.
ADHD was diagnosed by a Child and Adolescent Psychiatrist based on the DSM-IV criteria. Controls were selected from children attending the paediatric clinic. Childhood Sleep Questionnaire was used in assessment of sleep problems.

\section{Results}

Children with ADHD experienced restless leg syndrome, fear of sleeping alone and darkness more than the control group. They sleep later and need more rituals for sleep.

\section{Conclusions}

TChildren with ADHD should be assessed for sleep disturbances and offered interventions when needed.

SL J Psychiatry 2013; 4 (1): 14-17

\section{Introduction}

Attention deficit hyperactivity disorder (ADHD) is one of the commonest disorders seen in Child and Adolescent Psychiatry services. ADHD is characterised by inattention, impulsivity and hyperactivity $(1,2)$. The symptoms of ADHD last until adulthood in $65 \%$ of cases $(3,4)$. According to a systematic review of the epidemiology of ADHD in Iran, Tehran has the highest prevalence of ADHD (20\%), while Sanandaj has the lowest prevalence $(2.8 \%)(5)$.

ADHD is associated with comorbid conditions such as emotional problems, aggression, oppositional behaviours, specific learning disorders and sleep problems $(6,7)$. Irregular or disturbed sleep is not classified in the DSM IV (8). Sleep problems in children with ADHD can have an impact on the disease and pose a challenge for both parents and professionals (9).

Studies have shown that $25-50 \%$ of children with ADHD have sleep problems $(10,11)$. The types of sleep problems include insomnia, parasomnia, restless leg syndrome, jerky movements, nightmares, inadequate sleep, somnolence, day time sleepiness and low quality of sleep (12-14). Despite the high prevalence of sleep problems in children with ADHD, physicians usually treat inattention and hyper activity, and do not pay much attention to the treatment of sleep disorders. Improvement of sleep in children with ADHD results in improvement of the condition (11).

Several studies have described the epidemiology of ADHD in Iran, but these have not looked at sleep problems in these children $(15,16)$. The aim of the present study is to compare sleep problems in children with ADHD with that of a control group.

\section{Methods}

A cross-sectional study was conducted at the Child Psychiatry Clinic of Hazrat Rasoul Akram hospital in Tehran. Ninety children aged 6-12 years diagnosed with

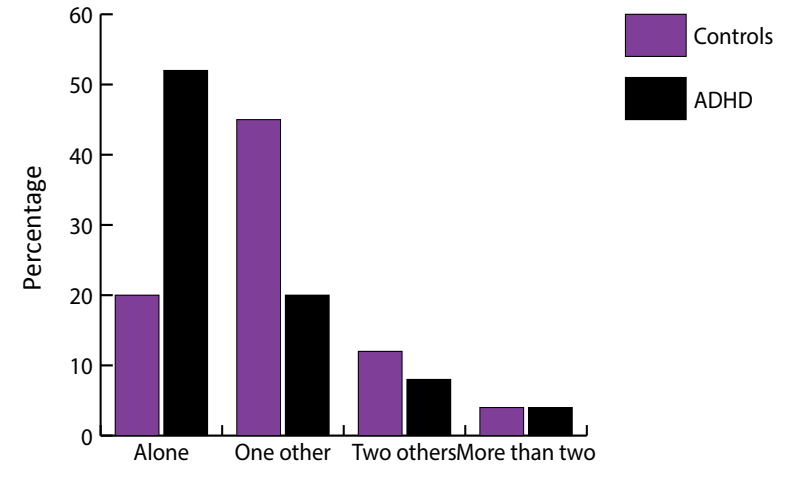

Fig. 1 Comparison of sleeping arrangements

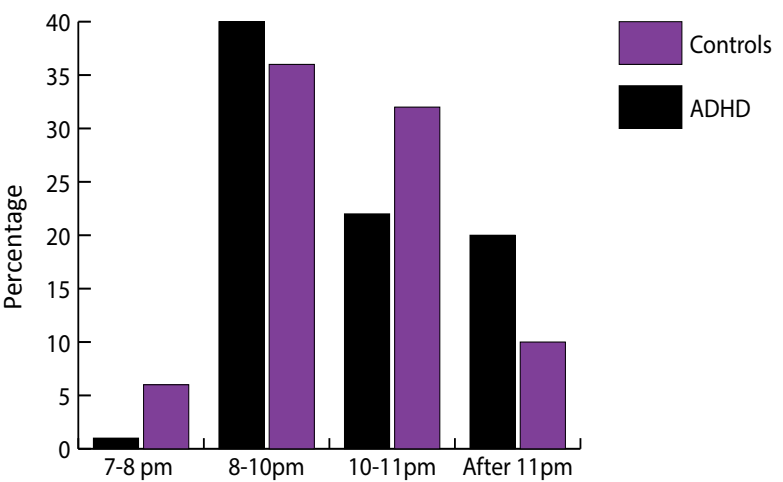

Fig. 2 Routine bedtime during school days 
Table 1 - Sleep related behaviours in children with ADHD and controls

\begin{tabular}{|c|c|c|c|}
\hline & $\begin{array}{l}\text { Children } \\
\text { with } \\
\text { ADHD } \\
\mathrm{N}(\%)\end{array}$ & $\begin{array}{l}\text { Controls } \\
\mathrm{N}(\%)\end{array}$ & $P$ value \\
\hline $\begin{array}{l}\text { Not going to bed on his/ } \\
\text { her own }\end{array}$ & $49(54.4)$ & 30 (33.3) & 0.004 \\
\hline $\begin{array}{l}\text { Needs to be with } \\
\text { parents when going to } \\
\text { bed }\end{array}$ & $40(44.4)$ & 31 (34.4) & NS \\
\hline $\begin{array}{l}\text { Shares the bedroom } \\
\text { with others }\end{array}$ & $32(35.6)$ & 26 (28.9) & NS \\
\hline $\begin{array}{l}\text { Wants to have toys in } \\
\text { the bed }\end{array}$ & $6(6.7)$ & 14 (15.6) & NS \\
\hline $\begin{array}{l}\text { Eating and drinking at } \\
\text { sleep time }\end{array}$ & $14(15.6)$ & $6(6.7)$ & NS \\
\hline $\begin{array}{l}\text { Sleeps with light turned } \\
\text { on }\end{array}$ & $28(31.1)$ & $29(32.2)$ & NS \\
\hline Distressed by noise & $10(11.1)$ & $22(24.4)$ & $p=0.01$ \\
\hline $\begin{array}{l}\text { Getting out of bed when } \\
\text { not asleep }\end{array}$ & $19(21.1)$ & $36(40)$ & $p=0.06$ \\
\hline Waking during the night & $6(6.7)$ & 10 (11.1) & NS \\
\hline Talking during sleep & $4(4.4)$ & 10 (11.1) & NS \\
\hline Sleep walking & $4(4.4)$ & $2(2.2)$ & NS \\
\hline Bruxism & $14(15.6)$ & $6(6.7)$ & NS \\
\hline $\begin{array}{l}\text { Having nightmares or } \\
\text { distressing dreams }\end{array}$ & $14(15.6)$ & $2(2.2)$ & $p=0.002$ \\
\hline $\begin{array}{l}\text { Shaking or banging the } \\
\text { head }\end{array}$ & $6(6.7)$ & $2(2.2)$ & NS \\
\hline $\begin{array}{l}\text { Crying or screaming } \\
\text { while asleep }\end{array}$ & 0 & $2(2.2)$ & NS \\
\hline Wetting the bed at night & $4(4.4)$ & $2(2.2)$ & NS \\
\hline Snoring & $4(4.4)$ & $4(4.4)$ & NS \\
\hline Sleep apnoea & $2(2.2)$ & 0 & NS \\
\hline $\begin{array}{l}\text { Repetitive movements } \\
\text { during sleep }\end{array}$ & $16(17.8)$ & $2(2.2)$ & NS \\
\hline $\begin{array}{l}\text { Waking up to go to the } \\
\text { toilet }\end{array}$ & $10(11.1)$ & $6(6.7)$ & NS \\
\hline Leg jerking & $22(24.4)$ & $6(6.7)$ & $p=0.001$ \\
\hline $\begin{array}{l}\text { Complain of leg pain or } \\
\text { discomfort or feel the } \\
\text { need to move }\end{array}$ & $6(6.7)$ & 0 & $p=0.01$ \\
\hline $\begin{array}{l}\text { Feeling dysphoric on } \\
\text { awakening }\end{array}$ & $20(22.2)$ & 10 (11.1) & $p=0.04$ \\
\hline $\begin{array}{l}\text { Sleepiness during day } \\
\text { time }\end{array}$ & $4(4.4)$ & 0 & $p=0.04$ \\
\hline Morning headache & $2(2.2)$ & 0 & NS \\
\hline Light sleep & $9(9.28)$ & 12 (13.3) & $p=0.01$ \\
\hline $\begin{array}{l}\text { Watching TV before } \\
\text { going to sleep }\end{array}$ & $36(40)$ & $8(8.9)$ & $p<0.001$ \\
\hline Refusing to go to bed & $34(37.8)$ & 12 (13.3) & $p<0.001$ \\
\hline $\begin{array}{l}\text { Awakening in a good } \\
\text { mood }\end{array}$ & $46(51.1)$ & 70 (77.8) & $p<0.001$ \\
\hline $\begin{array}{l}\text { Open mouth breathing } \\
\text { during day }\end{array}$ & $22(24.4)$ & $6(6.7)$ & $p<0.001$ \\
\hline $\begin{array}{l}\text { Rituals associated with } \\
\text { sleeping }\end{array}$ & 28 (31.1) & $6(6.7)$ & $p<0.001$ \\
\hline
\end{tabular}

NS=Not significant
ADHD were compared with controls $(n=90)$ without ADHD. ADHD was diagnosed based on the DSMIV criteria, by a Child and Adolescent Psychiatrist. Controls were selected from children attending the paediatric clinic. Exclusion criteria for the control group were history of ADHD, having a chronic neurologic or psychiatric disorders. Demographic data was collected from parents. Childhood Sleep Questionnaire was used to assess sleep problems. Childhood Sleep Questionnaire is a self-reported instrument and assesses sleep difficulties with 44 questions. Sleep disturbance is assessed using four ratings (Never, sometimes, usually and nearly always). Data was analyzed using SPSS version 18. Chi-square test was used for comparison of the two groups.

\section{Results}

The ADHD group consisted of 80 boys and 10 girls with a mean age of 9.1 years (SD1.6). Control group consisted of 40 boys and 50 girls with mean age of 8.0 years (1.5).

Sex distribution was different in cases and controls. Female to male ratio in ADHD group was $1: 8$ and in the control group 1:0.8. This was because of higher prevalence of ADHD in boys. Because the control group was selected from an outpatient paediatric clinic, the female: male ratio was similar among controls.

The rate of sleeping alone in children with ADHD is significantly lower than in the control group (figure 1) $(p<0.001)$. There was significant difference between the two groups in the duration of sleep, sleep latency and waking up time during holidays and school days.

Routine bed time during school days in the ADHD and control groups is shown in figure2. The number of children with ADHD who slept after $11 \mathrm{pm}$ on school days $(p=0.03)$ and slept after midnight during holidays $(p<0.001)$ was significantly higher than in the control group.

Table 1 compares sleep related behaviours between cases and controls. Nightmares, moving while sleeping, legs moving during sleep, sleepiness during daytime and refusal to go to sleep was significantly more in children with ADHD.

\section{Discussion}

Sleep disturbances were significantly more in children with ADHD compared the control group in 22 out of 44 categories. Sleeping alone was less frequent in children affected by ADHD and they slept later during school days and holidays compared to the control group. This can be due to higher anxiety, phobia or oppositional defiant disorder. It is also known that medication used to treat ADHD such as stimulants can cause sleep disturbance.

Other studies have shown some impairment in duration of sleep, sleep latency and awakening time in children with ADHD (17-19) . A systematic review of sleep 
disturbances also showed different duration of sleep and sleep latency. There were changes in the stages of sleep and sleep insufficiency in children with ADHD (20). The parents of our patients reported fatigue on waking up, day time sleepiness and lack of deep sleep in children with ADHD. This can be interpreted as a change in the sleep structure.

We found no difference in sleep latency between the two groups. A study by Hvolby et al on 206 children aged 5-11 years, show that long sleep latency and irregularity in sleep pattern in ADHD group are higher than in the control group (17).

It was reported in our study that children with ADHD breathe through the open mouth during the day time more than the control group. In a study in Taiwan, it has been shown that ADHD is associated with respiratory problems during sleep, day time sleepiness, napping, sleep irregularity and parasomnias (20). Our patients showed higher sleepiness but parasomnias like talking during sleep and sleepwalking was not significantly different.

In this study, pain or jerking of feet during sleep was significantly more in children with ADHD. This can be due to restless leg syndrome. However this was elicited as a response to one question and the diagnosis should be confirmed by a comprehensive clinical evaluation.

Although refusing to go to bed can be due to early insomnia, it also could be due to oppositional behaviour, fear or anxiety which is associated with ADHD. These findings are consistent with other research that restless leg syndrome, overactivity and respiratory problems during sleep and early insomnia are more common in children with ADHD (18).

Children in ADHD group were more likely to experience dysphoric mood on waking up. This may be due to mood dysregulation in ADHD.

Rituals associated with sleeping, fear of sleeping alone and fear of darkness in children with ADHD may be due to comorbid anxiety and sense of insecurity.

Ivanenko et al showed in a study of 174 children in France, that sleep disturbances are more common in children with psychiatric disorders such as anxiety disorders and mood disorders (19). In our study we found that fearful dreams and distress due to noise at night are more common in children with ADHD.

Sung et al assessed 239 families with children affected by ADHD, and found lower quality of life. Therefore sleep disturbances affect both individual and family functioning negatively. Sleep influences physical, emotional, cognitive and social development. Comorbid sleep disturbances exacerbates medical and psychiatric disorders (21).

This study had several limitations. It assessed sleep problems using a questionnaire. A clinical evaluation is necessary for a comprehensive assessment of sleep problems. We were also not able to assess the impact of stimulants used to treat ADHD on sleep.

\section{Conclusions}

Sleep disturbances are commoner in children with ADHD than in the control group. This is known to affect quality of life and functioning of the patient and family negatively. Future studies should assess the association of severity of ADHD symptoms, functioning level and adherence to treatment, with sleep disturbance in children with ADHD.

\section{Acknowledgement}

The authors would like to thanks staff of pediatric clinic in Hazrate-Rasoule- Akram hospital. This paper is based on a postgraduate thesis submitted for a psychiatric degree at the Tehran University of Medical Sciences.

\section{Declaration of interest \\ None declared}

\section{H Shooshtari, Associate Professor,}

Iran University of Medical Sciences, Mental Health Research Centre of Tehran Psychiatric institute, Tehran, Iran

Reza Bidaki, Assistant Professor of Psychiatry

Rafsanjan University of Medical Sciences, Rafsanjan, Iran

J Fili, Psychiatrist,

Iran University of Medical Sciences, Tehran, Iran

H Zarafshan Clinical Psychologist

Corresponding author: Reza Bidaki

E mail: Reza.Bidaki222@gmail.com

\section{References}

1. American Psychiatric Association. Diagnostic and Statistical Manual of Mental Disorders, 4th edn. text revision, Washington, DC: American Psychiatric Association, 2000

2. Rowland, AS, Lesesne, CA, Abramowitz, AJ.The epidemiology of attention-deficit/hyperactivity disorder (ADHD):a public health view. Ment Retard Dev Disabil Res Rev 2002; 8(3): 162-170

3. Spencer T, Biederman J, Wilens TE, Faraone SV. Adults with attention-deficit/hyperactivity disorder: A controversial diagnosis. J Clin Psychiatry 1998;59 Suppl 7:59-68

4. Elliott $\mathrm{H}$. Attention deficit hyperactivity disorder in adults: A guide for the primary care physician. South Med J 2002;95(7):736-42

5. Hakim shooshtary M, Chimeh N, Najafi M et al. The prevalence of Attention Deficit Hyperactivity Disorder in Iran: A systematic review. Iran J Psychiatry 2010; 5: 88-92

6. Kaplan H, Saddok B. Comprehensive Textbook of Psychiatry, 6th ed. Philadelphia. Lippincott, 2005.

7. Konofal E, Lecendreux M, Cortese S. Sleep and ADHD. Sleep Med 2010;11(7) 652-8

8. Cohen-Zion M, Ancoli-Israel S. Sleep in children with attention-deficit hyperactivity disorder (ADHD): a review of naturalistic and stimulant intervention studies. Sleep Med Rev 2004; 8(5):379-402

9. O'Brien LM, Gozal D. Sleep in children with attention deficit/hyperactivity disorder. Minerva Pediatr 2004;56(6):585-601 
10. Cohen-Zion M, Ancoli-Israel S. Sleep in children with attentiondeficit/ hyperactivity disorder ADHD: A review of naturalistic and stimulant intervention studies. Sleep Med Rev 2004; 8(5): 379-402.

11. Betancourt-Fursow de Jimenez YM, Jimenez-Leon JC, Jimenez-Betancourt CS. Attention deficit hyperactivity disorder and sleep disorders. Rev Neurol 2006; 42 Suppl 2:S37-51

12. Cortese S, Lecendreux M, Mouren MC, Konofal E. ADHD and insomnia. J Am Acad Child Adolesc Psychiatry 2006;45:384-5.

13. Van der Heijden KB, Smits MG, Van Someren EJ, Gunning WB. Idiopathic chronic sleep onset insomnia in attentiondeficit/hyperactivity disorder: a circadian rhythm sleep disorder. Chronobiol Int 2005;22:559-70

14. Cortese S, Konofal E, Lecendreux M, et al., Restless Legs Syndrome and attention-deficit/hyperactivity disorder: a review of the literature. Sleep 2005;28 (8):1007-13

15. Abdollahian E, Shakeri MT, Vosoogh E. [A study of attention deficit hyperactivity disorder (ADHD) prevalence in pre-school age children from March 2003 to June 2003 in Mashhad (Persian)]. Medical Journal of Mashad University of Medical Sciences 2004; 85: 280-275.
16. Khoushabi K, Pour etemad H, Mohammadi M, Houman A, Biglarian A, Towfigh N. Prevalence of attention deficit hyperactivity disorder and other co existing disorder among school students in Tehran (Persian). Investigation 2002; University of Social Welfare and Rehabilitation Sciences.

17. Hvolby A, Jorgensen J, Bilenberg N.Actigraphic and parental reports of sleep difficulties in children with attention deficit/hyperactivity disorder. Arch Pediatr Adolesc Med 2008;162 (4): 323-9

18. Lecendreux M, Cortese S. Sleep problems associated with ADHD: a review of current therapeutic options and recommendations for the future. Expert Rev Neurother 2007; 7(12):1799-806

19. Ivanenko A, Crabtree VM, Obrien LM, Gozal D. Sleep complaints and psychiatric symptoms in children evaluated at a pediatric mental health clinic. J Clin Sleep Med 2006; 2(1):42-48

20. Mindell JA, Owens JA. Diagnosis and Management of Sleep Problems. Philadelphia: Lippincott Williams \& Wilkins; 2003.

21. Sung V., Hiscock H, Sciberras E, EfronD. Sleep problems in children with attention-deficit/hyperactivity disorder: prevalence the effect on the child and family. Arch Pediatr Adolesc Med 2008; 162(4): 336-4 